\title{
The Efficacy of Parent Training Interventions for Disruptive Behavior Disorders in Treating Untargeted Comorbid Internalizing Symptoms in Children and Adolescents: A Systematic Review
}

\author{
Eleni Zarakoviti ${ }^{1} \cdot$ Roz Shafran $^{1,2} \cdot$ Danai Papadimitriou $^{3} \cdot$ Sophie D. Bennett ${ }^{1,2}$ (D)
}

Accepted: 17 April 2021 / Published online: 15 May 2021

(c) The Author(s) 2021

\begin{abstract}
Disruptive behavior disorders (DBDs) are among the primary reasons for child and youth referrals to mental health services and are linked to poor adult outcomes including antisocial behavior disorder. Research indicates a high incidence of internalizing problems in those with DBDs and those who have DBDs with cooccurring internalizing problems may have more severe later outcomes. Interventions targeted at internalizing symptoms have been found to also reduce comorbid externalizing problems. The impact of treatments for DBDs on comorbid internalizing disorders is not known. Databases PsycINFO, EMBASE and MEDLINE were systematically searched based on the Cochrane guidelines for systematic reviews. Records were independently reviewed by two reviewers. 12 papers were deemed eligible. A quality assessment of the selected studies was conducted independently by both reviewers. The 12 studies included 1334 young people with a mean age of 5 years. The parent training interventions assessed were the Incredible Years (6/12 studies), Triple-P (5/12) and Tuning In To Kids (1/12). 11 of the 12 studies reported significant reductions in primary externalizing behavior problems and DBDs. 7 studies reported significant reductions in internalizing symptoms. Mechanisms of change, clinical implications and directions for future research are discussed.
\end{abstract}

Keywords Disruptive behavior disorder $\cdot$ Intervention $\cdot$ Parent training $\cdot$ Children $\cdot$ Adolescents

\section{Introduction}

Disruptive Behavior Disorders (DBDs) are among the most frequent reasons for child and adolescent referrals to mental health services (Hood \& Eyberg, 2003; Katzmann et al., 2019). DBDs often develop in childhood or adolescence (Turner, Hu, Villa and Nock 2018) and have been linked to high rates of criminality and antisocial personality disorder in adulthood, as well as to poor outcomes in terms of employment and social relations (Gacono, Nieberding,

Sophie D. Bennett

sophie.bennett.10@ucl.ac.uk

1 Population, Policy and Practice Research and Teaching Department, UCL Great Ormond Street Institute of Child Health, 30 Guilford Street, London WC1N 1EH, UK

2 Great Ormond Street Hospital NHS Foundation Trust, Great Ormond Street, London WC1N 3JH, UK

3 Imperial College London, South Kensington, London SW7 2BU, UK
Owen, Rubel, \& Bodholdt, 2001; Bjorseth \& Wichstrom, 2016).

Research indicates a high incidence of internalizing problems in those with DBDs, estimated at around 20\% (Polier et al. 2012; Stalk et al. 2015) and those who have DBDs with co-occurring internalizing problems may have more severe later outcomes (Eisenberg et al. 2001; Fraire \& Ollendick, 2013). Conversely, it is also possible for anxiety disorders to be a protective factor for young people with DBDs (Cunningham \& Ollendick, 2010) and individual patient metaanalyses suggest that co-occurring emotional problems do not attenuate the impact of group parenting programmes for DBDs (Leijten et al. 2020). However, whilst there is excellent evidence demonstrating the efficacy of behavioral parenting interventions for DBDs (Fonagy et al. 2015), there is little guidance to suggest the optimal treatment for children with DBDs and co-occurring internalizing disorders. Previous evidence suggests that treating the co-occurring anxiety disorder with cognitive behavioral therapy for anxiety is also effective in reducing symptoms of DBDs (Kreuze et al. 2018; Mahdi et al. 2019). However, it is not known whether 
treatment for behavioral disorders impacts on co-occurring internalizing disorders.

Given the high comorbidity between conduct and internalizing disorders, it is clinically relevant to explore the optimal treatment strategy (Loeber et al. 2000; Stalk et al. 2015). Therapists may prioritise treatment of externalizing over internalizing problems when faced with comorbidity (Milette-Winfree \& Mueller, 2018) but it is not clear whether research evidence supports such an approach. As internalizing disorder interventions are effective in reducing co-occurring externalizing behavior problems (Mahdi et al. 2019), it may be that the opposite is also true. The aim of the review was therefore to determine the impact of behavior interventions for the treatment of disruptive behavior in children and young people on comorbid internalizing symptoms.

\section{Method}

A systematic literature review was performed according to the Cochrane guidelines for systematic reviews (Higgins, Thomas, Chandler, Cumpston, Li, Page et al. 2019). The review was registered on the PROSPERO International Register of Systematic reviews (CRD42020176693).

The databases PsycINFO, EMBASE and MEDLINE were searched in January 2021 using the following search terms: ((triple p or incredible years or parenting program*) and (adolescen* or teen* or child* or toddler*) and (conduct disorder or oppositional defiant disorder or child behavi* or agress* behavi* or antisocial behavi*) and (double-blind or random* assigned or control)). There were no date restrictions on records retrieved. The records retrieved from this search were screened for eligibility based on the inclusion and exclusion criteria described below. Reference lists and citations of included articles were also searched for relevant articles.

\section{Inclusion Criteria}

\section{Participants}

i. Children and adolescents between the ages of 0 and 18

ii. Participants who were either given a DBD diagnosis according to the Diagnostic and Statistical Manual (DSM) $3^{\text {rd }}$ revised edition, $4^{\text {th }}$ and $5^{\text {th }}$ edition (American Psychiatric Association, 1987, 2000, 2013) or the International Statistical Classification of Diseases, 10th revision (ICD 10; World Health Organization, 2004) or scored at clinical level on a standardized validated measure of disruptive behavior symptoms, such as the Strengths and Difficulties Questionnaire (SDQ; Goodman, 1999), the Eyberg Child Behavior Inven- tory (ECBI; Eyberg \& Pincus, 1999) or the Achenbach Child Behavior Checklist (CBCL; Achenbach \& Rescorla, 2000). Participants were not required to have internalizing symptoms above a clinical threshold.

\section{Intervention}

i. Parent training interventions targeting elevated externalizing behavior problems or DBDs

\section{Comparator}

i. Randomized controlled trials with a treatment as usual or waitlist control

\section{Outcome}

i. A measure of externalizing behavior problems

ii. A measure of internalizing symptoms

\section{Exclusion Criteria}

i. Studies assessing non-behavioral interventions, such as music therapy

ii. Studies that focused on the treatment of conditions other than DBDs, such as ADHD, or anxiety disorders

iii. Studies not available in English

iv. Trials on young people with no or sub-threshold disruptive behavior concerns

\section{Study Selection}

Study selection was performed by comparing all records against the aforementioned inclusion and exclusion criteria. This process was independently performed by two reviewers (EZ \& DP). Qualified clinical psychologists (RS \& SB) were consulted to resolve any disagreements and discrepancies concerning the final selection of eligible studies.

\section{Data Extraction}

A data extraction form was developed, consisting of the study and sample characteristics, and the main outcomes. Data was extracted independently by two reviewers (EZ \& DP). Interrater reliability was $80 \%$.

\section{Assessment of Risk of Bias}

An assessment of risk of bias was performed independently by two reviewers (EZ \& DP) using The Effective Public Health Practice Project (EPHPP, 2019a, b). Cohen's kappa for interrater reliability was $75 \%$ (McHugh, 2012). 
Each study was initially evaluated as strong, moderate or weak on the following domains: selection bias, study design, confounders, blinding, data collection methods, withdrawals and dropouts, based on EPHPP criteria. A final rating score was then assigned to each study based on the total number of domains that were scored as weak. Studies with no weak ratings were considered strong; those with one weak rating were deemed moderate, while those with two or more weak ratings were regarded as weak (Higgins et al. 2011).

\section{Results}

The initial search identified 687 records, of which 416 remained after duplicates were removed. A total of 12 met the criteria for inclusion in the current systematic review. A flow chart of the search process stages along with reasons for inclusion and exclusion can be found in Fig. 1. Details on the selected studies' characteristics can be found in Table 1.

\section{Quality Assessment}

According to the EPHPP, four of the twelve studies were deemed strong (Larsson et al. 2009; Morpeth et al. 2017; Patterson et al. 2002; Scott et al. 2010); another five were rated as moderate (Axberg \& Broberg, 2012; Baker et al. 2017; Meybodi et al. 2019; Schappin et al. 2013; WebsterStratton \& Herman, 2008), and the remaining three were deemed weak (Palmer et al. 2019; Sanders et al. 2012; Wiggins et al. 2009) (Table 1). Cohen's kappa for interrater reliability was high at 75\% (McHugh, 2012).

\section{Study Characteristics}

\section{Participants}

A total of 1334 children and young people were enrolled in the studies. In all studies reviewed, the majority of participants were male, except for one study in which the sample's gender distribution is not mentioned (Patterson et al. 2002). Participants' ages ranged between 2 and 10 years, with a mean age of 5 years. In only one study did participants receive a formal, secondary internalizing disorder diagnosis (Webster-Stratton \& Herman, 2008). In the remaining 11 studies, 3 had samples with a mean internalizing score above the clinical threshold for an internalizing disorder at baseline (Meybodi et al. 2019; Morpeth et al. 2017; Schappin et al. 2013).

\section{Intervention}

The majority of the studies in this review tested the efficacy of the Incredible Years (Axberg \& Broberg, 2012; Larsson et al. 2009; Morpeth et al. 2017; Patterson et al. 2002;
Scott et al. 2010; Webster-Stratton \& Herman, 2008) and the Triple P (Baker et al. 2017; Palmer et al. 2019; Sanders et al. 2012; Schappin et al. 2013; Wiggins et al. 2009) parent training intervention programs. Scott and colleagues (2010) assessed the Incredible Years parent training program combined with the Child Literacy Program. Finally, one study assessed the Tuning In To Kids parent training intervention (Meybodi et al. 2019).

The majority of the interventions were delivered face to face and were led by professionals qualified to deliver each intervention (Axberg \& Broberg, 2012; Larsson et al. 2009; Meybodi et al. 2019; Morpeth et al. 2017; Palmer et al. 2019; Patterson et al. 2002; Schappin et al. 2013; Scott et al. 2010; Webster-Stratton \& Herman, 2008; Wiggins et al. 2009). In two studies on the Triple $\mathrm{P}$ intervention, the program was delivered online (Baker et al. 2017; Sanders et al. 2012). The protocols for each intervention used in the studies were similar in format, number of sessions and overall duration as all intervention procedures were conducted in accordance with the relevant manualized guidelines indicated for each intervention (The Incredible Years, 2013; Triple P International, 2020; Tuning In To Kids, 2020). On average, the interventions lasted 10-12 sessions and the majority of those, except for those assessing online interventions, were conducted in group format (Axberg \& Broberg, 2012; Larsson et al. 2009; Meybodi et al. 2019; Morpeth et al. 2017; Palmer et al. 2019; Patterson et al. 2002; Schappin et al. 2013; Scott et al. 2010; Webster-Stratton \& Herman, 2008; Wiggins et al. 2009).

\section{Comparators}

In the majority of studies (10/12) the intervention groups were compared to a waitlist control group (Axberg \& Broberg, 2012; Baker et al. 2017; Larsson et al. 2009; Meybodi et al. 2019; Morpeth et al. 2017; Patterson et al. 2002; Schappin et al. 2013; Scott et al. 2010; Webster-Stratton \& Herman, 2008; Wiggins et al. 2009). One study assessing the Triple P Online Intervention included an 'internet use as usual' control group (Sanders et al. 2012). One study compared a sufficient exemplar Triple $\mathrm{P}$ discussion group (providing examples of how to apply parenting strategies to promote generalization of skills learnt to different situations) to a single exemplar, narrowly focused control group - the Triple P Dealing with Disobedience Discussion Group (Palmer et al. 2019).

\section{Outcome}

The primary DBD diagnosis was established according to the DSM criteria (Axberg \& Broberg, 2012; Larsson et al. 2009; Scott et al. 2010; Webster-Stratton \& Herman, 2008) or based on clinically elevated scores on validated disruptive 


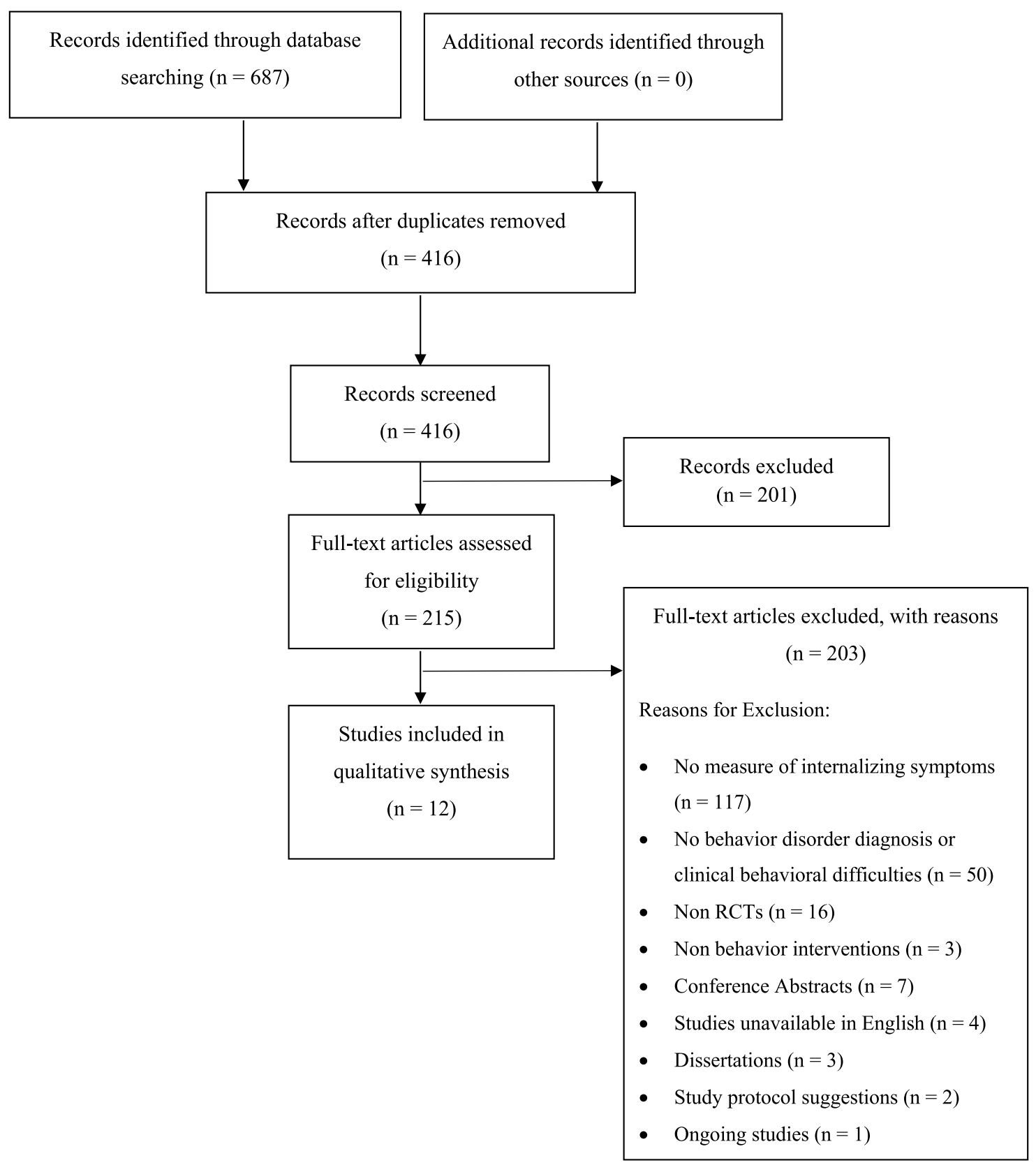

2

Fig. 1 Prisma diagram

behavior measures such as the ECBI (Palmer et al. 2019; Patterson et al. 2002; Sanders et al. 2012; Webster-Stratton \& Herman, 2008), the SDQ (Baker et al. 2017; Morpeth et al. 2017; Scott et al. 2010; Wiggins et al. 2009) and the CBCL (Meybodi et al. 2019; Schappin et al. 2013) scales.

To measure externalizing symptoms from pre- to posttreatment and at follow up, the majority of studies used the ECBI (Axberg \& Broberg, 2012, Baker et al. 2012, Larsson et al. 2009; Meybodi et al. 2019; Morpeth et al. 2017; Palmer et al. 2019; Patterson et al. 2002; Sanders et al. 2012; Schappin et al. 2013; Scott et al. 2010; Webster-Stratton \& Herman, 2008). Other measures used were the SDQ (Morpeth et al. 2017; Patterson et al. 2002; Sanders et al. 2012) and the CBCL (Schappin et al. 2013; Wiggins et al. 2009). Two studies used direct observations of child behavior and parent-child interactions (Sanders et al. 2012; Scott et al. 2010); 


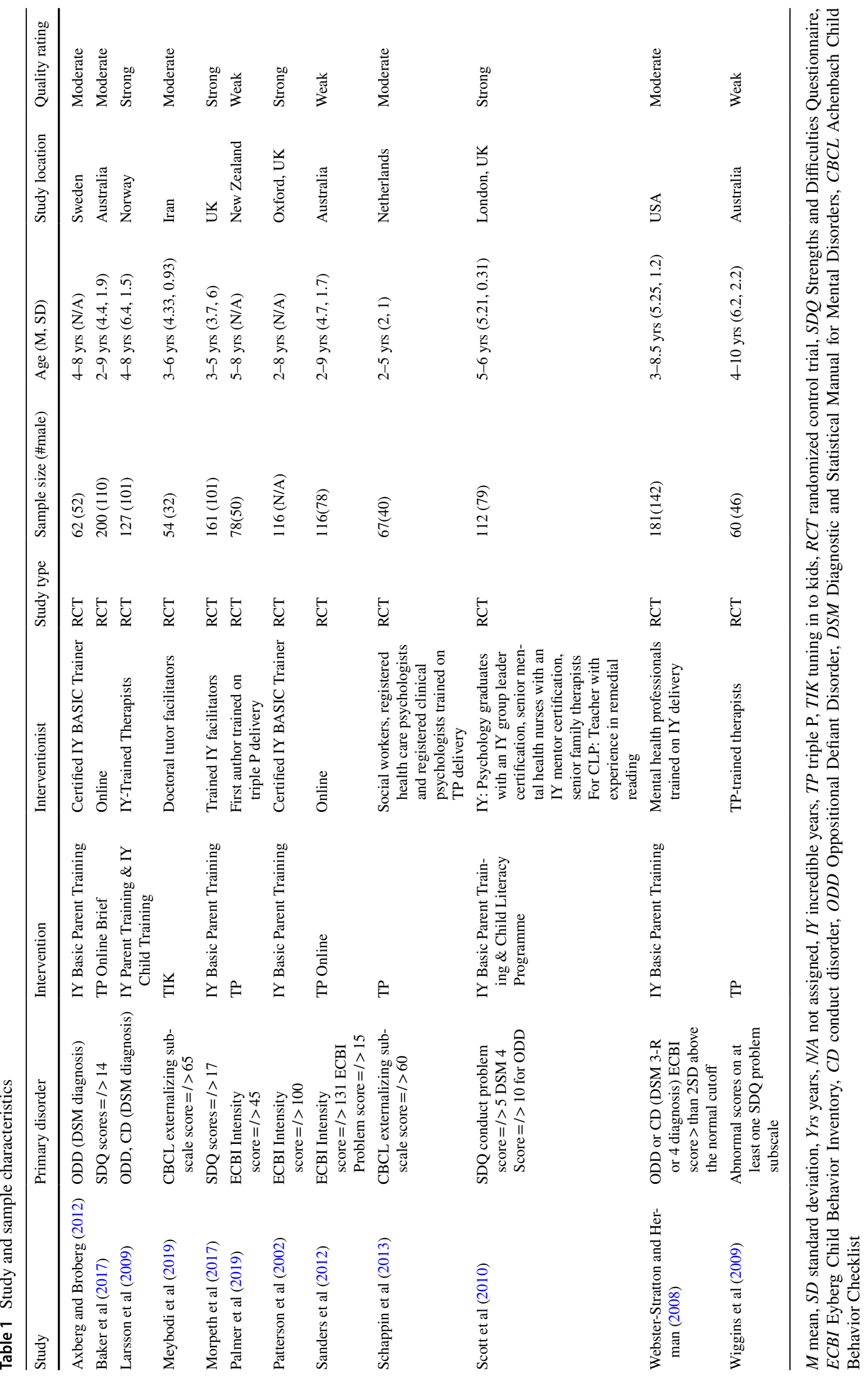


one used teacher reports of child behavior (Schappin et al. 2013); one (Baker et al, 2017) used the Child Adjustment and Parent Efficacy Scale (CAPES) (Morawska et al. 2014) with the remaining study using the Parent Account of Child Symptoms (PACS) scale (Scott et al. 2010).

Internalizing scores were, in most studies, measured via the relevant internalizing symptom subscales on the SDQ (Axberg \& Broberg, 2012; Morpeth et al. 2017; Palmer et al. 2019; Patterson et al. 2002; Sanders et al. 2012) and the CBCL (Larsson et al. 2009; Schappin et al. 2013; Webster-Stratton \& Herman, 2008; Wiggins et al. 2009). Other measures included the CAPES (Baker et al. 2017), the ECBI (Schappin et al. 2013), the PACS (Scott et al. 2010) and the Persian version of the Emotion Regulation Checklist (ERC) (Meybodi et al. 2019).

\section{Intervention Efficacy on Primary Externalizing and Comorbid Internalizing Symptoms}

\section{The Incredible Years Program}

Primary Externalizing Behavior Problems All six studies assessing the efficacy of the Incredible Years Program indicated significant reductions on ECBI behavior problem and intensity scores from pre- to post-treatment and at subsequent follow ups. These reductions were deemed clinically and statistically significant both within the parent training intervention group and between the intervention and control groups. Incredible Years effectively reduced both the number and the frequency of disruptive behavior problems (Axberg \& Broberg, 2012; Larsson et al. 2009; Morpeth et al. 2017; Patterson et al. 2002; Scott et al. 2010; WebsterStratton \& Herman, 2008).

Comorbid Internalizing Symptoms Four of the six studies assessing the Incredible Years found significant reductions in internalizing scores (Larsson et al. 2009; Morpeth et al, 2017; Patterson et al, 2002; Webster-Stratton \& Herman, 2008). Only one of these included participants with a formal, secondary internalizing disorder diagnosis at baseline (Webster-Stratton \& Herman, 2008). One study found significant reductions in mother but not father reported CBCL internalizing scores for the intervention group from pre- to post-treatment and follow-up compared to the control group (Larsson et al. 2009). Patterson and colleagues (2002) found that although SDQ internalizing scores were reduced from pre- to post-treatment for the intervention group, these effects were not maintained at the subsequent 6-month follow up, where scores for the control group were lower. Two studies indicated no significant reduction in internalizing symptom scores from pre- to post-treatment and follow up, neither within the Incredible Years intervention group nor between the intervention and control groups (Axberg \& Broberg, 2012; Scott et al. 2010).

\section{The Triple P Program}

Primary Externalizing Behavior Problems Five studies assessed the efficacy of the Triple P program (Baker et al. 2017; Palmer et al. 2019; Sanders et al. 2012; Schappin et al. 2013; Wiggins et al. 2009), with three of these considered 'weak' according to the quality rating (Palmer et al. 2019; Sanders et al. 2012; Wiggins et al. 2009). Of these five, three indicated that Triple $\mathrm{P}$ led to significant reductions on the ECBI behavior problem and intensity scale scores, both between the Triple P condition and the control group and within the Triple $P$ group from pre- to post-treatment and follow up (Baker et al. 2017; Palmer et al. 2019; Sanders et al. 2012). However, in Palmer and colleagues' (2019) study, these intervention effects were significant only in mother, not father reports of child conduct problems. One study indicated significant reductions on the CBCL externalizing problem scores (Wiggins et al. 2009), while Sanders and colleagues (2012), also found significant reductions on both the SDQ externalizing problem scores and observed child conduct problems between the intervention condition and control group from pre- to post-treatment and follow up. Finally, one study found no significant differences in child behavioral outcomes between the Triple $\mathrm{P}$ intervention group and the control group nor within the Triple $\mathrm{P}$ group across the different time points. In fact, behavior problems decreased slightly, non-significantly in both groups (Schappin et al. 2013).

Comorbid Internalizing Symptoms Of the five studies looking at the efficacy of Triple P, only three found significant reductions in comorbid internalizing scores at post treatment and follow up compared to baseline and all three of these were considered 'weak' studies according to the quality ratings (Palmer et al. 2019; Sanders et al. 2012; Wiggins et al. 2009). Of these three, two studies reported significantly lower scores on the SDQ emotional subscale from pre- to post-treatment and follow up for the Triple $\mathrm{P}$ intervention condition, but not for the control condition (Palmer et al. 2019; Sanders et al. 2012). Wiggins and colleagues (2009) indicated significantly lower internalizing symptom scores on the CBCL for the intervention condition. However, the difference in CBCL scores between the control and intervention conditions were not statistically significant (Wiggins et al. 2009).

Finally, two studies indicated no significant reductions in co-occurring internalizing symptom scores from preto post-treatment and follow up, neither within the Triple $\mathrm{P}$ group nor between the control and intervention groups (Baker et al. 2017; Schappin et al. 2013). 


\section{The Tuning In To Kids Program}

Primary Externalizing Behavior Problems One study assessed the efficacy of the Tuning In To Kids program (Meybodi et al. 2019). Results indicated significant reductions in mother reported child behavior problems on the ECBI problem and intensity scores from pre- to post-treatment and follow up in the Tuning In To Kids intervention condition only. Results were also significant between the intervention and control group as mothers in the control condition did not report significant reductions in child conduct problems (Meybodi et al. 2019).

Comorbid Internalizing Symptoms In Meybodi et al.'s (2019) study assessing Tuning In To Kids, scores on the ERC significantly improved and decreased from pre- to post-treatment in the intervention group compared to the control group.

\section{Discussion}

\section{Main Findings}

The purpose of the current review was to determine the impact of parent training intervention programs specifically aimed at treating externalizing behavior problems on comorbid internalizing symptoms in children and adolescents.

A total of twelve Randomized Controlled Trials were reviewed. Overall, the results indicated that parent training programs designed to treat conduct problems may positively affect co-occurring internalizing concerns; Seven of the twelve studies found significant reductions in internalizing symptoms in the intervention group compared to the control group, from pre- to post-treatment and at subsequent follow ups. However, only one (Webster-Stratton \& Herman, 2008 - rated 'moderate' on quality) included children with a diagnosis of a cooccurring anxiety disorder. Three of the seven studies finding significant reductions were considered weak. Of the seven demonstrating significant reductions in internalizing symptoms, three used the Incredible Years program (Larsson et al. 2009; Morpeth et al. 2017; Webster-Stratton \& Herman, 2008), one used the Tuning In To Kids programme (Meybodi et al, 2019) and the remaining three used the Triple P program (Palmer et al. 2019; Sanders et al. 2012; Wiggins et al. 2009). One study on the Incredible Years program indicated reductions in comorbid internalizing symptom measures at post treatment, however these effects were not maintained at follow up (Patterson et al. 2002). The remaining four studies demonstrated some reductions in internalizing symptoms in the intervention versus the control conditions, but these reductions were not statistically significant despite significant reductions in externalizing symptoms compared to the control group. Two of these studies assessed the Incredible Years intervention (Axberg \& Broberg, 2012; Scott et al. 2010) and another two the Triple P intervention (Baker et al. 2017; Schappin et al. 2013). All four studies received moderate or strong quality ratings, supporting the reliability and validity of their results: Three were deemed moderate (Axberg \& Broberg, 2012; Baker et al. 2017; Schappin et al. 2013) while the remaining one was deemed strong (Scott et al. 2010) according to the quality assessment. However, in none of these four studies did the subjects meet the diagnostic criteria to receive a secondary internalizing disorder diagnosis nor were their internalizing symptoms significantly elevated at baseline. Therefore, the non-significant reductions in internalizing symptom measures found in these four studies may be due to symptoms being low from baseline, making it harder to identify change.

\section{Mechanisms of Change}

The results of this systematic review suggest that interventions focused on treating primary behavior disorder diagnoses or clinical-level behavioral symptoms may also have a positive impact on comorbid internalizing symptoms. A number of potential mechanisms may explain this effect. DBDs often present with internalizing symptoms (Burcusa et al. 2003; Angold, Costello \& Erkanli, 2003) and the underlying psychopathology of the two conditions may overlap. For example, evidence has indicated that negative emotionality may be a risk factor for both categories of disorders (Nigg \& Huang-Pollock, 2003; Wolff \& Ollendick, 2006). Therefore, certain basic aspects of behavior interventions may be applied to benefit the treatment of various conditions. Empirical evidence by Brumariu and Kerns (2010) suggested a link between the quality of the parent-child attachment and the development of internalizing symptoms. In particular, insecure attachment styles (avoidant, anxious or disorganized) were linked to a greater likelihood of developing anxiety and mood disorders like depression (Brumariu \& Kerns, 2010).

Internalizing symptoms may also present as a consequence of externalizing behavior problems (Fonagy et al. 2015). Research by Gilliom and Shaw (2004) found that early childhood externalizing problems were followed by later internalizing symptom development. Intervention for DBDs may eliminate the secondary, comorbid internalizing symptoms that stem from the primary disorder. However, ten of the twelve studies had a waitlist control and not an active control. Further research with active control groups would enhance understanding of the mechanisms of change. 


\section{Strengths of this Systematic Review}

The present systematic literature review is the first to address the efficacy of behavior-focused parent training interventions on comorbid conditions. The findings of this review partially confirm the initial hypothesis that parent training treatment strategies that are aimed at targeting externalizing behavior problems may also successfully improve comorbid internalizing symptoms. Given the high prevalence of behavioral problems in children and adolescents (Hood \& Eyberg, 2003; Katzmann et al. 2019), in addition to the high comorbidity between internalizing and externalizing behavior problems in young people (Fonagy et al. 2015), the data from this systematic review effectively addresses and responds to a gap in the scientific literature regarding appropriate treatment strategies to manage such comorbidities.

Among the strengths of the present review is the replicable search strategy applied based on the Cochrane guidelines for systematic reviews (Higgins et al. 2019). Extensive and specific search terms were used to cover all pertinent ages, interventions, primary diagnoses and comorbidities, in order to maximize the relevance of the articles retrieved. Strict inclusion and exclusion criteria were applied to reliably determine eligibility. Records were screened for eligibility by two independent reviewers to support the validity and reliability of the final set of articles included in the review. The review includes RCTs only.

\section{Limitations and Suggestions for Future Research}

In addition to the strengths and limitations of the included studies described above, the review itself also had some limitations. Firstly, in almost all of the records assessed, comorbid internalizing symptoms were secondary outcomes and were usually not mentioned in the abstracts or key terms of the studies. It is therefore possible that some studies were missed in the original search.

Secondly, the current review assessed intervention efficacy in reducing co-occurring internalizing symptom measures. However, participants had a formal secondary internalizing disorder diagnosis in only one study (Webster-Stratton \& Herman, 2008). In the majority of studies, internalizing symptom measures were assessed through reports such as the SDQ, ECBI or CBCL. These internalizing symptom measures are not specific to particular disorders and it may be useful for future research to use more distinct measures of internalizing problems in future trials of disruptive behaviour interventions. In addition, in most studies, scores on these measures were below clinical cutoffs at baseline. This may limit both the power to find a true effect if one exists and the ability to conclude whether interventions targeting behavior disorders are also able to target co-occurring internalizing disorders as opposed to symptoms alone. Future research should also consider evidence from studies in which subjects score above clinical cutoffs or have a formal diagnosis for both externalizing and internalizing conditions.

\section{Clinical Implications}

The current systematic literature review indicated the efficacy of the Incredible Years, Triple P and Tuning In To Kids parent training behavior interventions on untargeted comorbid internalizing symptoms in young people. Given the high rates of comorbidity between externalizing and internalizing conditions in children and adolescents, knowledge on appropriate intervention strategies to treat both primary and secondary diagnoses is important to be applied in clinical practice (Stalk et al. 2015). The majority of research on psychiatric comorbidity so far has focused on using transdiagnostic treatment approaches targeting both conditions simultaneously or applying distinct interventions to target each one of the comorbid conditions separately (Marchette \& Weisz, 2017). However, evidence from this review suggests that disorder-specific interventions may also be effective in targeting cooccurring symptoms. A disorder-specific intervention approach may allow for increased treatment adherence and fidelity both due to their time and cost-effectiveness and because following multiple treatment protocols at once may be overwhelming and has been linked to higher dropout rates (Dretzke, Frew, Davenport, Barlow, StewartBrown, Sandercock et al. 2005; Dretzke et al. 2009; Levy et al. 2007). It may be helpful to see whether internalizing symptoms improve in response to treatment of DBD treatment and then consider whether additional treatment for internalizing problems is needed, and vice versa. Therefore, clinicians should be informed on the benefits of disorderspecific interventions in order to apply them in practice.

\section{Conclusion}

The findings of the current systematic review overall confirm the robust efficacy of the Incredible Years, Triple P and Tuning In To Kids parent training behavior interventions in reducing externalizing behavior difficulties in children and adolescents presenting with DBDs or elevated behavior problem scores that are within the clinical range. Although findings for comorbid internalizing symptoms were less consistent, internalizing symptom measures were significantly reduced in the majority of the studies assessed. Therefore, parent training programs targeted at the treatment of externalizing behavior problems may also effectively address comorbid internalizing symptoms at the same time. 
Authors' Contributions EZ, SB \& RS developed the study protocol. EZ and DP completed the searches, data extraction and quality analysis under supervision of SB \& RS. EZ, SB and RS wrote the manuscript and all authors reviewed the final submission.

Funding All research at Great Ormond Street Hospital NHS Foundation Trust and UCL Great Ormond Street Institute of Child Health is made possible by the NIHR Great Ormond Street Hospital Biomedical Research Centre. The views expressed are those of the author(s) and not necessarily those of the NHS, the NIHR or the Department of Health.

Availability of data and material Data are available upon reasonable request.

\section{Declarations}

Conflict of interest The authors do not have any Conflicts of Interest to report.

Open Access This article is licensed under a Creative Commons Attribution 4.0 International License, which permits use, sharing, adaptation, distribution and reproduction in any medium or format, as long as you give appropriate credit to the original author(s) and the source, provide a link to the Creative Commons licence, and indicate if changes were made. The images or other third party material in this article are included in the article's Creative Commons licence, unless indicated otherwise in a credit line to the material. If material is not included in the article's Creative Commons licence and your intended use is not permitted by statutory regulation or exceeds the permitted use, you will need to obtain permission directly from the copyright holder. To view a copy of this licence, visit http://creativecommons.org/licenses/by/4.0/.

\section{References}

Achenbach, T. M., \& Rescorla, L. A. (2000). Achenbach System of Empirically Based Assessment (ASEBA) Preschool Forms \& Profiles. University of Vermont, Research Center for Children, Youth and Families.

American Psychiatric Association. (1987). Diagnostic and Statistical Manual of Mental Disorders. (3rd ed. revised). Washington, DC.

American Psychiatric Association. (2000). Diagnostic and Statistical Manual of Mental Disorders. (4th ed.). American Psychiatric Association.

American Psychiatric Association. (2013). Diagnostic and Statistical Manual of Mental Disorders. (5th ed.). American Psychiatric Association.

Angold, A., Costello, E. J., \& Erkanli, A. (2003). Comorbidity. Journal of Child Psychology and Psychiatry, 40(1), 57-87. https:// doi.org/10.1111/1469-7610.00424

Axberg, U., \& Broberg, A. G. (2012). Evaluation of "the incredible years" in Sweden: the transferability of an American parenttraining program to Sweden. Scandinavian Journal of Psychology, 53(3), 224-232. https://doi.org/10.1111/j.1467-9450.2012. 00955.x

Baker, S., Sanders, M. R., Turner, K. M. T., \& Morawska, A. (2017). A randomized controlled trial evaluating a low-intensity interactive online parenting intervention, Triple P Online Brief, with parents of children with early onset conduct problems. Behaviour Research and Therapy, 91, 78-90. https://doi.org/ 10.1016/j.brat.2017.01.016
Bjorseth, A., \& Wichstrom, L. (2016). Effectiveness of Parent-Child Interaction Therapy (PCIT) in the Treatment of Young Children's Behavior Problems. A Randomized Controlled Study. PLoS ONE, 11(9), e0159845. https://doi.org/10.1371/journal. pone. 0159845

Brumariu, L. E., \& Kerns, K. A. (2010). Parent-child attachment and internalizing symptoms in childhood and adolescence: A review of empirical findings and future directions. Development and Psychopathology, 22(1), 177-203. https://doi.org/10.1017/S0954 579409990344

Burcusa, S. L., Iacono, W. G., \& McGue, M. (2003). Adolescent twins discordant for major depressive disorder: Shared familial liability to externalizing and other internalizing disorders. Journal of Child Psychology and Psychiatry, 44(7), 997-1005. https://doi.org/10. 1111/1469-7610.00184

Cunningham, N. R., \& Ollendick, T. H. (2010). Comorbidity of anxiety and conduct problems in children: Implications for clinical research and practice. Clinical Child and Family Psychology Review, 13(4), 333-347. https://doi.org/10.1007/ s10567-010-0077-9

Dretzke, J., Davenport, C., Frew, E., Barlow, J., Stewart-Brown, S., Bayliss, S., et al. (2009). The clinical effectiveness of different parenting programmes for children with conduct problems: A systematic review of randomised controlled trials. Child and Adolescent Psychiatry and Mental Health, 3(1), 7. https://doi.org/10. 1186/1753-2000-3-7

Dretzke, J., Frew, E., Davenport, C., Barlow, J., Stewart-Brown, S., Sandercock, J., Bayliss, S., \& Raftery, J., Hyde, C. \& Taylor, R. (2005). The effectiveness and cost-effectiveness of parent training/ education programmes for the treatment of conduct disorder, including oppositional defiant disorder, in children. NIHR Health Technology Assessment programme: Executive Summaries. Retrieved January 12, 2021 from https://www.ncbi.nlm.nih.gov/ books/NBK62292/

Eisenberg, N., Cumberland, A., Spinrad, T. L., Fabes, R. A., Shepard, S. A., Reiser, M., et al. (2001). The relations of regulation and emotionality to children's externalizing and internalizing problem behavior. Child Development, 72(4), 1112-1134. https://doi.org/ 10.1111/1467-8624.00337

EPHPP. (2009a). Quality Assessment Tool for Quantitative Studies. EPHPP. Retrieved January 12, 2021 from https://merst.ca/wpcontent/uploads/2018/02/quality-assessment-tool_2010.pdf

EPHPP. (2009b). Quality Assessment Tool for Quantitative Studies: Dictionary. EPHPP. Retrieved January 12, 2021 from https:// merst.ca/wp-content/uploads/2018/02/qualilty-assessment-dicti onary_2017.pdfr

Eyberg, S. M., \& Pincus, D. (1999). Eyberg Child Behavior Inventory and Sutter-Eyberg student behavior Inventory-Revised: Professional Manual. Psychological Assessment Resources.

Fonagy, P., Cottrell, D., Phillips, J., Bevington, D., Glaser, D., \& Allison, E. (2015). What Works For Whom? A Critical Review of Treatments for Children and Adolescents. Guilford Publications.

Fraire, M. G., \& Ollendick, T. H. (2013). Anxiety and oppositional defiant disorder: A transdiagnostic conceptualization. Clinical Psychology Review, 33(2), 229-240. https://doi.org/10.1016/j. cpr.2012.11.004

Gacono, C. B., Nieberding, R. J., Owen, A. Rubel, J. \& Bodholdt, R. (2001). Treating Conduct Disorder, Antisocial and Psychopathic Personalities. In J. B. Ashford, B. D. Sales, \& W. H. Reid. (Eds.) Treating Adult and Juvenile Offenders with Special Needs (pp. 99-129). Washington, D.C., United States, American Psychological Association.

Gilliom, M., \& Shaw, D. S. (2004). Codevelopment of externalizing and internalizing problems in early childhood. Development and Psychopathology, 16(2), 313-333. https://doi.org/10.1017/s0954 579404044530 
Goodman, R. (1999). The extended version of the Strengths and Difficulties Questionnaire as a guide to child psychiatric caseness and consequent burden. Journal of Child Psychology and Psychiatry, 40(5), 791-799

Higgins, J. P., Altman, D. G., Gotzsche, P. C., Juni, P., Moher, D., Oxman, A. D., et al. (2011). The Cochrane Collaboration's tool for assessing risk of bias in randomised trials. BMJ, 343, d5928. https://doi.org/10.1136/bmj.d5928

Higgins, J., Thomas, J., Chandler, J., Cumpston, M., Li, T., Page, M. J. \& Welch V. A. (2019). Cochrane Handbook for Systematic Reviews of Interventions version 6.0. Cochrane Training. Retrieved January 12, 2021, from www.training.cochrane.org/ handbook

Hood, K. K., \& Eyberg, S. M. (2003). Outcomes of parent-child interaction therapy: mothers' reports of maintenance three to six years after treatment. Journal of Clinical Child and Adolescent Psychology, 32(3), 419-429. https://doi.org/10.1207/S15374424JCCP32 $03 \_10$

Katzmann, J., Goertz-Dorten, A., Hautmann, C., \& Doepfner, M. (2019). Social skills training and play group intervention for children with oppositional-defiant disorders/conduct disorder: Mediating mechanisms in a head-to-head comparison. Psychotherapy Research, 29(6), 784-798. https://doi.org/10.1080/10503 307.2018.1425559

Kreuze, L. J., Pijnenborg, G. H. M., de Jonge, Y. B., \& Nauta, M. H. (2018). Cognitive-behavior therapy for children and adolescents with anxiety disorders: A meta-analysis of secondary outcomes. Journal of Anxiety Disorders, 60, 43-57. https://doi.org/10.1016/j. janxdis.2018.10.005

Larsson, B., Fossum, S., Clifford, G., Drugli, M. B., Handegard, B. H., \& Morch, W. T. (2009). Treatment of oppositional defiant and conduct problems in young Norwegian children: Results of a randomized controlled trial. European Child and Adolescent Psychiatry, 18(1), 42-52. https://doi.org/10.1007/s00787-008-0702-z

Leijten, P. H. O., Scott, S., Landau, S., Harris, V., Mann, J., Hutchings, J., Beecham, J., \& Gardner, F. (2020). Individual participant data meta-analysis: Impact of conduct problem severity, comorbid ADHD and emotional problems, and maternal depression on parenting program effects. Journal of the American Academy of Child and Adolescent Psychiatry, 59(8), 933-943.

Levy, K., Hunt, C., \& Heriot, S. (2007). Treating comorbid anxiety and aggression in children. Journal of the American Academy of Child and Adolescent Psychiatry, 46(9), 1111-1118. https://doi.org/10. 1097/chi.0b013e318074eb32

Loeber, R., Burke, J. D., Lahey, B. B., Winters, A., \& Zera, M. (2000). Oppositional defiant and conduct disorder: a review of the past 10 years, part I. Journal of the American Academy of Child and Adolescent Psychiatry, 39(12), 1468-1484. https://doi.org/10. 1097/00004583-200012000-00007

Mahdi, M., Jhawar, S., Bennett, S. D., \& Shafran, R. (2019). Cognitive behavioral therapy for childhood anxiety disorders: What happens to comorbid mood and behavioral disorders? A systematic review. Journal of Affective Disorders, 251, 141-148. https://doi.org/10. 1016/j.jad.2019.03.041

Marchette, L. K., \& Weisz, J. R. (2017). Practitioner review: Empirical evolution of youth psychotherapy toward transdiagnostic approaches. Journal of Child Psychology and Psychiatry, 58(9), 970-984. https://doi.org/10.1111/jcpp.12747

McHugh, M. L. (2012). Interrater reliability: the kappa statistic. Biochem Med (Zagreb), 22(3), 276-282

Meybodi, F., Mohammadkhani, P., Pourshahbaz, A., Dolatshahi, B., \& Havighurst, S. S. (2019). Improving Parent Emotion Socialization Practices: Piloting Tuning in to Kids in Iran for Children With Disruptive Behavior Problems. Family Relations, 68(5), 596-607. https://doi.org/10.1111/fare.12387
Milette-Winfree, M., \& Mueller, C. W. (2018). Treatment-as-usual therapy targets for comorbid youth disproportionately focus on externalizing problems. Psychological Services, 15(1), 65-77. https://doi.org/10.1037/ser0000162

Morawska, A., Sanders, M. R., Haslam, D., Filus, A., \& Fletcher, R. (2014). Child adjustment and parent efficacy scale: Development and initial validation of a parent report measure. Australian Psychologist, 49(4), 241-252

Morpeth, L., Blower, S., Tobin, K., Taylor, R. S., Bywater, T., Edwards, R. T., et al. (2017). The effectiveness of the Incredible Years preschool parenting programme in the United Kingdom: A pragmatic randomised controlled trial. Child Care in Practice, 23(2), 141161. https://doi.org/10.1080/13575279.2016.1264366

Nigg, J. T., \& Huang-Pollock, C. L. (2003). An Early-Onset Model of the Role of Executive Functions and Intelligence in Conduct Disorder/ Delinquency. In B. B. Lahey, T. E. Moffitt, \& A. Caspi. (Eds). Causes of Conduct Disorder and Juvenile Delinquency. Guilford Publications.

Palmer, M. L., Keown, L. J., Sanders, M. R., \& Henderson, M. (2019). Enhancing outcomes of low-intensity parenting groups through sufficient exemplar training: A randomized control trial. Child Psychiatry and Human Development, 50(3), 384-399. https://doi. org/10.1007/s10578-018-0847-z

Patterson, J., Barlow, J., Mockford, C., Klimes, I., Pyper, C., \& Stewart-Brown, S. (2002). Improving mental health through parenting programmes: block randomised controlled trial. Archives of Disease in Childhood, 87(6), 472-477. https://doi.org/10.1136/ adc. 87.6.472

Polier, G. G., Vloet, T. D., Herpertz-Dahlmann, B., Laurens, K. R., \& Hodgins, S. (2012). Comorbidity of conduct disorder symptoms and internalising problems in children: investigating a community and a clinical sample. European Child and Adolescent Psychiatry, 21(1), 31-38. https://doi.org/10.1007/s00787-011-0229-6

Sanders, M. R., Baker, S., \& Turner, K. M. (2012). A randomized controlled trial evaluating the efficacy of Triple P Online with parents of children with early-onset conduct problems. Behaviour Research and Therapy, 50(11), 675-684. https://doi.org/10.1016/j. brat.2012.07.004

Schappin, R., Wijnroks, L., Uniken Venema, M., Wijnberg-Williams, B., Veenstra, R., Koopman-Esseboom, C., et al. (2013). Brief parenting intervention for parents of NICU graduates: a randomized, clinical trial of Primary Care Triple P. BMC Pediatrics, 13, 69. https://doi.org/10.1186/1471-2431-13-69

Scott, S., Sylva, K., Doolan, M., Price, J., Jacobs, B., Crook, C., et al. (2010). Randomised controlled trial of parent groups for child antisocial behaviour targeting multiple risk factors: the SPOKES project. Journal of Child Psychology and Psychiatry, 51(1), 48-57. https://doi.org/10.1111/j.1469-7610.2009.02127.x

Stalk, H.-L., Love, A. R., \& Mueller, C. W. (2015). Age of conduct disorder onset and comorbid anxiety and depression. The Journal of Forensic Psychiatry \& Psychology, 26(3), 337-350. https://doi. org/10.1080/14789949.2015.1017593

The Incredible Years. (2013). The Incredible Years. Retrieved January 12, 2021 from http://www.incredibleyears.com

Triple P International. (2020). TRIPLE P IN A NUTSHELL. Retrieved January 12, 2021, from https://www.triplep.net/glo-en/find-outabout-triple-p/triple-p-in-a-nutshell/

Tuning In To Kids. (2020). What is Tuning in to Kids?. Tuning In To Kids. Retrieved January 12, 2021, from https://tuningintokids.org. au/about/what-is-tuning-in-to-kids/

Turner, B. J., Hu, C., Villa, J. P. \& Nock, M. K. (2018). Oppositional Defiant Disorder and Conduct Disorder. In K. M. Scott, P. de Jonge, D. J. Stein, \& R. C. Kessler. (Eds.) Mental disorders around the world: Facts and figures from the WHO World Mental 
Health Surveys. (pp. 209-222). Cambridge, UK, Cambridge University Press

Webster-Stratton, C., \& Herman, K. C. (2008). The impact of parent behavior-management training on child depressive symptoms. Journal of Counseling Psychology, 55(4), 473-484. https://doi. org/10.1037/a0013664

Wiggins, T. L., Sofronoff, K., \& Sanders, M. R. (2009). Pathways Triple P-positive parenting program: effects on parent-child relationships and child behavior problems. Family Process, 48(4), 517-530. https://doi.org/10.1111/j.1545-5300.2009.01299.x

Wolff, J. C., \& Ollendick, T. H. (2006). The comorbidity of conduct problems and depression in childhood and adolescence. Clinical
Child and Family Psychology Review, 9(3-4), 201-220. https:// doi.org/10.1007/s10567-006-0011-3

World Health Organization. (2004). The ICD-10 International Classification of Mental and Behavioral Disorders (2ed.). Geneva, Switzerland.

Publisher's Note Springer Nature remains neutral with regard to jurisdictional claims in published maps and institutional affiliations. 